\title{
Cuidado parental e promoção do desenvolvimento infantil no contexto da prematuridade
}

\author{
Camila Camargo Medeiros (iD \\ Universidade de Brasília - Brasília - DF - Brasil
}

Mariana André Honorato Franzoi (iD

Universidade de Brasília - Brasília - DF - Brasil

\author{
Aline Oliveira Silveira (iD \\ Universidade de Brasília - Brasília - DF - Brasil
}

\section{RESUMO}

Objetivo: Compreender os antecedentes, as práticas e a influência do cuidado parental no desenvolvimento da criança nascida prematura. Métodos: Estudo de delineamento transversal e abordagem qualitativa-interpretativa realizado com 7 pais de crianças nascidas prematuras em acompanhamento em ambulatório de crescimento e desenvolvimento de um hospital de ensino do Distrito Federal. A coleta de dados ocorreu em dezembro de 2017 e janeiro de 2018 por meio da estratégia de entrevista aberta em profundidade, além da construção do genograma e ecomapa da família, na perspectiva dos pais, como estratégia complementar. A análise dos dados teve como referencial metodológico a Pesquisa de Narrativas e referencial teórico, o Interacionismo Simbólico, desvelou quatro categorias temáticas: crenças, medo e insegurança parental; natureza do cuidado e conceito de maternidade e paternidade; aprendizados e práticas parentais; e apoio social. Resultados: As narrativas revelaram insegurança e medo dos pais para cuidar dos filhos em casa após a alta hospitalar, em especial pela imaturidade do prematuro, mas apesar disso procuram oferecer o suporte necessário para manutenção do cuidado, valorizando pequenos detalhes e conquistas desenvolvimentais da criança frente aos inúmeros desafios e limitações de apoio social que enfrentam no cotidiano. Conclusão: Os conhecimentos, crenças e valores que sustentam as práticas parentais no contexto da prematuridade têm repercussões na vida e na adaptação dos pais ao nascimento e cuidado do prematuro. O engajamento da equipe de saúde deve ser constante para promover a autonomia, a segurança, a eficácia e o bem-estar parental no cuidado desenvolvimental do filho prematuro.

Descritores: Recém-Nascido Prematuro; Desenvolvimento Infantil; Conhecimento; Pais; Pesquisa Qualitativa.

\section{INTRODUÇÃO}

A prematuridade é considerada um importante problema de saúde pública, global e complexo. Estima-se que, anualmente, nascem cerca de 15 milhões de neonatos prematuros (antes de completar 37 semanas de gestação) e que este número é crescente ${ }^{(1)}$. Estimativas mostram que, no ano de 2014 , aproximadamente $10,6 \%$ de todos os nascidos vivos no mundo eram prematuros ${ }^{(2)}$. As ocorrências de nascimentos prematuros variaram de $13,4 \%$ no norte da África a $8,7 \%$ na Europa ${ }^{(2)}$. No Brasil, a taxa de prematuridade, em 2014 , foi de $11,18 \%{ }^{(2)}$ o que o coloca entre os dez países do mundo com maior número de nascimentos prematuros ${ }^{(1)}$.

Destaca-se que a ocorrência de nascimentos prematuros está relacionada com indicadores sociais e econômicos, sendo maior em países de baixa renda ${ }^{(1)}$. Assim, dentro desses países, as famílias pobres estão em maior risco(1).

A complicações associadas à prematuridade se constituem como uma das principais causas de morte entre crianças menores de 5 anos $^{(3)}$. A maioria destas mortes poderia ter sido evitada com intervenções atuais e de baixo custo como aquecimento, apoio à amamentação e cuidados básicos para infecções e dificuldades respiratórias ${ }^{(1)}$. Ademais, as iniquidades no acesso aos cuidados neonatais adequados e a não otimização da tecnologia tem gerado um aumento da carga de incapacidades, comorbidades e necessidades especiais em saúde entre os prematuros que sobrevivem ao período neonatal ${ }^{(1)}$.

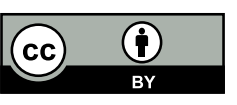

Este artigo está publicado em acesso aberto (Open Access) sob a licença Creative Commons, que permite uso, distribuição e reprodução em qualquer meio, sem restrições, desde que o trabalho seja corretamente citado.
Este artigo foi selecionado, corrigido e aprovado pelo $8^{\circ}$ Ciaiq - Congresso Ibero-Americano em Investigação Qualitativa, 2019, seguindo suas normas e formatação. 
As causas do nascimento prematuro são complexas e variam entre países e regiões ${ }^{(1)}$. Sabe-se que crianças muito prematuras (entre 28 e 32 semanas de idade gestacional) ${ }^{(1)}$ e as prematuras extremas (abaixo de 28 semanas de idade gestacional)(1) têm maior risco de déficits neurodesenvolvimentais e de inadequado desempenho das funções executivas (autorregulação, memória de trabalho e flexibilidade mental) necessárias à aprendizagem; e que os estilos parentais podem influenciar de forma positiva ou negativa o desenvolvimento da criança( ${ }^{(4)}$, sendo que a parentalidade sensível e mutualidade podem proteger crianças nascidas prematuras enquanto que a parentalidade controladora e hostil pode estar relacionada aos déficits ${ }^{(5)}$.

A parentalidade é definida como um conjunto de fatores, por meio dos quais os progenitores/cuidadores da criança, asseguram, de acordo com suas competências e habilidades, as condições de vida necessárias para proporcionar o desenvolvimento pleno da criança em um ambiente seguro, englobando os níveis físico, psicológico e social, objetivando torná-la progressivamente mais autônoma( ${ }^{(6)}$.

Dentre as transições do ciclo de vida, a parentalidade pode constituir uma tarefa difícil e desencadeadora de estresse. A prematuridade possui implicações ainda maiores na construção da parentalidade, pois exige dos pais ajustes mais complexos e competências adicionais para lidar com a sua criança prematura( ${ }^{(7)}$.

Nesse processo, podem vivenciar dificuldades e necessitar de apoio de profissionais de saúde para o desenvolvimento da parentalidade efetiva. Os pais se sentem com medo, preocupados, desamparados, impotentes, culpados e estressados, bem como que o nascimento prematuro pode estar associado a problemas de saúde física e psicológica entre os pais ${ }^{(8)}$. Além disso, têm-se relações bem estabelecidas entre as dificuldades de cuidar do prematuro e o estresse psicológico sofrido pelos pais durante a hospitalização na Unidade de Cuidados Intensivos Neonatais $(\mathrm{UTIN})^{(9)}$, apontando-a como uma barreira ao reconhecimento do ser pai/mãe e à construção da parentalidade.

No que se refere ao conhecimento, estudo com mães de prematuros ressalta que apresentaram dificuldades tanto em descrever o desenvolvimento infantil normal quanto o desenvolvimento relacionado à prematuridade. Constatou-se que, mesmo diante de atrasos desenvolvimentais, as mães não relacionaram esses comprometimentos com a prematuridade ${ }^{(10)}$.

Uma meta-síntese sobre a experiência dos pais de prematuros após a alta da UTIN, mostra que é um fenômeno caracterizado por ansiedade nos primeiros momentos, permeado por sentimentos ambíguos de alívio e medo ${ }^{(9)}$. O medo e a ansiedade vivenciados por esses pais resultam da insegurança e despreparo em promover os cuidados necessários ao filho após a alta $^{\left({ }^{(9)}\right.}$. No entanto, esses são bem gerenciados se o suporte adequado for fornecido aos pais ${ }^{(9)}$.

As experiências dos pais são construídas no processo de cuidar e nas interações estabelecidas com o neonato prematuro, que requer acolhimento e apoio adequado dos profissionais para melhorar a confiança e autonomia parental; capacitar e fortalecer os pais no manejo dos desafios; melhorar o conhecimento e reduzir as complicações, especialmente as associadas à parentalidade superprotetora ${ }^{(9)}$.

Diversos fatores influenciam no modo como os pais se relacionam com o filho prematuro e o cuidado, como: as crenças, as concepções, a história e o contexto de vida, fatores econômicos, sociais, culturais e políticos, entre outros, que geram diferentes visões e necessidades de adaptação à situação(11).

Assim, programas de apoio e intervenção precoce são essenciais para promover a parentalidade nos nascimentos prematuros $^{(12)}$, com destaque para aqueles que adotam a filosofia do cuidado centrado na família. Essa perspectiva envolve a equipe neonatal, considera as experiências dos pais e requer mudanças de práticas para criar um ambiente de apoio às necessidades parentais e promotor da participação ativa nos cuidados com o filho de forma precoce (desde os momentos iniciais na UTIN) e contínua, com seguimento após a alta hospitalar ${ }^{(13)}$.

A compreensão das sutilezas das experiências é fundamental para a efetivação de um cuidado centrado na família, a fim de possibilitar aos pais o crescimento pós-traumático ${ }^{(8)}$. $O$ apoio sensível ao processo vivenciado pelos pais de prematuros, permite uma ressignificação e a reconstrução positiva das suas experiências, como a compreensão alterada de si mesmos, dos outros e da própria vida ${ }^{(8)}$. Esse conhecimento instrumentaliza os profissionais de saúde para intervirem ajudando os pais a ativarem a sua rede social, a reconhecerem a importância dos cuidados mútuos, a enxergarem além dos ideais culturais em relação ao parto e à vida familiar, assim como, encontrarem suas próprias soluções para o cotidiano(8).

Considerando a especificidade dessa experiência de transição para a parentalidade, delimitou-se como questão da pesquisa quais os conhecimentos, crenças e valores que sustentam o cuidado parental no contexto da prematuridade, como se manifestam nas interações e como influenciam no desenvolvimento da criança nascida prematura? Assim, o objetivo do estudo foi compreender os antecedentes, as práticas e a influência do cuidado parental no desenvolvimento da criança nascida prematura. 


\section{MÉTODOS}

Trata-se de uma pesquisa de delineamento transversal e abordagem qualitativa-interpretativa, realizada no ambulatório de crescimento e desenvolvimento de um hospital de ensino na cidade de Brasília, Distrito Federal, Brasil, referência no acompanhamento de crianças de risco habitual e de crianças com necessidades especiais de cuidados em saúde, com destaque para o seguimento de prematuros.

Para a captação dos participantes adotou-se a amostragem por conveniência e estabeleceram-se como critérios de inclusão ser pai ou mãe de criança nascida prematura em acompanhamento no ambulatório de crescimento e desenvolvimento. Como critério de exclusão consideraram-se pais e mães de crianças portadoras de comorbidades associadas à prematuridade (malformações congênitas, síndromes genéticas, entre outras).

O convite para participar da pesquisa foi realizado em momento oportuno na sala de espera do ambulatório, em linguagem clara e concisa, respeitando-se as condições socioculturais de cada participante. Nesta ocasião eram fornecidas informações sobre as pesquisadoras e o desenho de pesquisa prospectado. Diante do aceite, procediase a leitura compreensiva do Termo de Consentimento Livre e Esclarecido (TCLE) e o Termo de Autorização para Utilização de Imagem e Som de Voz para fins de pesquisa e a oficialização da participação na pesquisa deu-se após a assinatura do participante e da pesquisadora responsável.

A coleta de dados ocorreu nos meses de dezembro de 2017 e janeiro de 2018. Utilizou-se como estratégia metodológica a entrevista aberta em profundidade, considerando-se os pressupostos da pesquisa narrativa de compreensão de experiência como histórias vividas e narradas ${ }^{(14)}$, iniciada com uma ampla questão norteadora, que neste estudo foi: Você acredita que a forma como cuida do seu filho prematuro tem influenciado o seu desenvolvimento? Como? Também foram introduzidas perguntas intermediárias a fim de aprofundar descrições, reflexões e articulações entre os aspectos narrados e, desse modo, obter densidade de conteúdo. Adotou-se como estratégia complementar a construção do genograma e ecomapa da família, na perspectiva dos pais ${ }^{(15)}$.

As entrevistas foram realizadas em local privado, áudio-gravadas e tiveram duração média de 50 minutos. A gravação foi realizada para facilitar a obtenção de diálogo e evitar a perda de dados significativos. As entrevistas foram transcritas na íntegra e as narrativas foram identificadas pelo termo "família", seguido do número correspondente à ordem cronológica da realização das entrevistas, resultando na codificação F01, F02, ...F07, garantido assim o anonimato dos participantes. Ressalta-se que trata-se de uma pesquisa relativa à família, uma vez que considerouse as respostas individuais de membros da família (pais) como unidade de análise ${ }^{(16)}$.

A amostra final foi composta por 7 pais de crianças nascidas prematuras. $O$ critério adotado para a suspensão das entrevistas foi o de saturação teórica. Para tanto, considerou-se o desenho e escopo do estudo, assim como a riqueza dos dados ${ }^{(17)}$ e a representação, em quantidade e intensidade, das múltiplas dimensões do fenômeno, da qualidade das ações e das interações, do aprofundamento, da abrangência e da diversidade no processo de compreensão da experiência ${ }^{(18)}$.

Os dados foram analisados pelo método da pesquisa de narrativas, na perspectiva holística com ênfase no conteúdo que consiste em leitura reiterativa de forma empática do material coletado, na tentativa de se estabelecer um núcleo central, um foco da história como um todo; apontamento das impressões globais iniciais; especificação dos termos ou focos de conteúdo a serem seguidos na reconstrução da história; e por fim, retomada da leitura reflexiva da história( ${ }^{(19)}$. Nesse processo, foram considerados os elementos chave que compõem o espaço tridimensional do método da pesquisa de narrativa, a saber: a interação (pessoal e social), a continuidade (presente, passado e futuro) e a situação (lugar) ${ }^{(14)}$. A interpretação dos dados foi fundamentada no referencial teórico do Interacionismo Simbólico ${ }^{(20,21)}$.

Esta pesquisa foi aprovada pelo Comitê de Ética em Pesquisa (CEP) da Faculdade de Ciências da Saúde sob Parecer no 1.325.884, e atendeu aos preceitos éticos da Resolução 466/2012 do Conselho Nacional de Saúde em todas as suas etapas.

\section{RESULTADOS}

\section{Caracterização dos pais e neonatos prematuros}

Participaram do estudo sete pais, sendo seis mães e um pai de crianças nascidas prematuras que acompanhavam o(a) filho(a) na consulta ambulatorial. A idade variou entre 26 a 39 anos, e quanto ao estado civil dos participantes, todos se encontravam casados ou em união estável. Dos sete entrevistados, quatro possuíam ensino médio 
completo e três ensino superior completo, apenas duas mães não exerciam atividade remunerada e dedicavam-se exclusivamente aos cuidados da casa e dos filhos.

Quanto à composição das famílias, eram predominantemente nucleares (pai, mãe, filhos), entretanto, duas dessas famílias eram extensas, onde os avós e tios da criança residiam no mesmo domicílio. Já as redes sociais dessas famílias são formadas pelo apoio dos familiares, da igreja, do ambiente de trabalho e pelas instituições de saúde que frequentam.

Os dados referentes aos recém-nascidos revelaram que a idade gestacional variou de 26 a 33 semanas e o tempo de internação de 23 a 123 dias e, quatro das crianças possuíam irmãos mais velhos.

No que se refere ao local de procedência, cinco dos entrevistados residem em Brasília e seu entorno e os outros dois são residentes de um município em Minas Gerais. Quanto à composição familiar, destaca-se que cinco participantes fazem parte de famílias nucleares e biparentais (pai ou padrasto mãe e seus filhos) e dois integram famílias extensas, onde os avós e tios da criança residiam no mesmo domicílio.

\section{Cuidado Parental e Promoção do Desenvolvimento da Criança Prematura}

As narrativas dos pais revelam as relações de medo, insegurança, de cuidados e de mudanças na construção da parentalidade, que foram construídas a partir do nascimento e convívio com o filho prematuro, permitindo acessar sentidos afetivos e emocionais. O núcleo central das histórias narradas foi construído segundo as vivências parentais no cuidado do filho em domicílio e da relevância do estímulo realizado, visando impulsionar seu desenvolvimento.

As experiências dos pais foram descritas em quatro categorias temáticas representativas dos processos interacionais vivenciados a partir do nascimento do filho prematuro, da temporalidade e da situação. Estas categorias são descritas a seguir, acompanhadas dos respectivos trechos das narrativas.

\section{Crenças, medo e insegurança parental}

O nascimento prematuro do filho ocasiona pensamentos e concepções de que o filho não iria sobreviver devido à antecipação do parto, ao baixo peso e ao tamanho do bebê. Diante dessa situação de incertezas, os pais relatam com unanimidade a necessidade da religiosidade e da fé em Deus:

"[...] aí eu pedia a Deus né, você confia em Deus, mas mesmo assim você fica com medo, eu tinha muito, muito medo mesmo. É uma coisa horrível não é, você fica vivendo um dia após o outro." (FO6)

"[...] mas aí eu apeguei com Deus, conversava tanto com ele, com meu filho sabe, nossa, foi difícil. Fiquei com muito medo, uma tensão, uma angústia assim, mas ele foi meu milagre. Eu estava fadada a perder meu filho, então quando ele nasceu, chorando e bem, nossa, foi a coisa mais linda do mundo. Meu milagre mesmo." (F07)

Ainda relacionado ao tamanho e à imaturidade do filho, os pais relatam receio de receberem alta hospitalar, pois terão que administrar as demandas e os cuidados da criança em casa sem ajuda da equipe de saúde. A rede de apoio mostra-se essencial nesta etapa, visto que é onde os pais buscam suporte quando preciso. Algumas mães ainda relatam que com o fim da licença maternidade, sentem culpa por serem obrigadas a delegar o cuidado do filho a outras pessoas, o que gera ainda mais angústia e tristeza com o distanciamento do filho:

“[...] mas quando ele foi pra casa, por ser um bebê muito pequeno, eu sempre imaginei assim: ah quando eu tiver meu filho vai ser tudo normal, mas nos primeiros meses foi difícil, medo, insegurança. Ligava pra minha mãe antes de fazer qualquer coisa, qualquer coisa estranha eu já perguntava se isso era normal ou não." (FO3) "Ah, eu acho que importante mesmo é o contato, essa questão de contato físico, essa questão do estar perto, como eu trabalho, quando eu tive que deixar ele pra voltar a trabalhar, pra mim foi um outro parto. Porque aí a gente perde essa questão do contato físico, principalmente para amamentar. Só que agora ele não está querendo mais, e eu fico: "oh filho, faz isso com sua mãe não", porque eu vou sentir mais falta que ele, por causa desse contato físico mesmo, desse "estar perto". (FO5)

Nos relatos, percebe-se que as dificuldades enfrentadas pelas famílias estão relacionadas à dificuldade de deslocamentos e da continuidade do tratamento. Visto que o nascimento prematuro necessita de um acompanhamento contínuo, os pais precisam levar os filhos para serviços de referência, tendo muitas vezes que faltar ao trabalho, percorrer longas distâncias, muitas vezes dependendo de transporte público, e delegar o cuidado dos outros filhos a familiares:

"Assim, para mim é um pouco difícil essa questão de ficar viajando não é, para trazer ela nas consultas, lá na cidade que eu moro é muito pequena e não tem esse acompanhamento pra ela. Às vezes a gente tem que vir 
até três vezes no mesmo mês, e isso se torna cansativo pra ela, pra gente, mas como é pro bem dela a gente está aqui toda vez que precisa." (F01)

\section{A natureza do cuidado e conceito de maternidade e paternidade}

O cuidado preciso e característico demandado pela criança prematura ocasiona nos pais uma transformação no conceito de maternidade/paternidade, pois quebra as definições pré-existentes sobre o que seria esse conceito, podendo até ser comparado com o nascimento de outros filhos a termo:

"Então, eu acho que o conceito de mãe que eu tinha mudou porque a gente sempre acha que vai ser uma coisa não é, aí quando ele chegou, passou por tanta coisa, parece que eu aprendi o que era ser mãe de verdade. Então mudou muito do que eu pensava que era ser mãe, mas foi a melhor coisa que aconteceu na minha vida." (F07)

"Mas a ideia que eu tinha antes de como era ser mãe mudou completamente, porque não foi tudo igual como eu imaginei, levar ele pra casa, cuidar dele, as coisinhas dele, não tinha quase nada pronto quando ele nasceu, então foi muito difícil assim, não é. Mas nossa, pra mim foi maravilhoso, mesmo com todos esses problemas, essas preocupações." (F03)

Ainda sobre o conceito de ser pai/mãe, a natureza do cuidado tem forte influência na construção desse significado, visto que o prematuro exige cuidados mais complexos e específicos. As narrativas também trazem o reconhecimento e a importância do contato com o filho. Os pais demonstram um engajamento com esse cuidado com a forma como estimulam o filho visando ao seu progresso e acreditam que esse cuidado, somado à presença e ao afeto, são essenciais para um desenvolvimento eficaz:

"Ah, acho que o cuidado em si né, que tem que ter com ele. Prestar atenção se alguma coisa ta errado[...] então eu acho que a gente sempre tem que ta atento pra essas coisas, qualquer coisa de diferente que acontece a gente tem que tá de olho." (F04)

\section{Aprendizados e práticas parentais}

Os pais trazem nos relatos a definição de prematuridade como uma precipitação, um bebê que nasceu antes do tempo e trouxe consigo um conjunto de inseguranças, medo e desafios. Apesar das dificuldades, os relatos trazem também sentimentos positivos como o amor, a gratidão e um maior apreço pela vida, visto que passam a comemorar e valorizar cada superação de seus filhos.

Após a alta hospitalar e a adaptação dos pais com a criança, o conceito de prematuridade, antes formulado por concepções pré-existentes, passa por uma reestruturação, ocasionado pela ressignificação das experiências vivenciadas. Esses pais passam a compreender que o filho irá se desenvolver, entretanto, de forma mais lenta e gradual, se comparado a uma criança nascida a termo:

"Bebê apressado não é?! Que veio antes da hora. Mas não é mais um bicho de sete cabeças, depois de tudo que a gente passou eu vejo que tem solução." (FO4)

"Aí ficamos aqui, no total, mais de 50 dias de internação. Mas assim, foi um dia após o outro, um dia de cada vez. [...] e assim, cada dia era um ganho, era uma vitória, uma vibração. E eu tentava focar nisso."(F05)

"[...] é só uma antecipação, mas não é um bicho de sete cabeças como a gente acha antes do bebê nascer, não

é. É uma coisa diferente não é, mas que tem a possibilidade da criança se desenvolver bem e normal." (F01)

Os pais buscam oferecer todo o suporte necessário para que a continuidade do cuidado ocorra. Relatam o empenho para levar o filho às consultas ambulatoriais e de estimulação precoce, sempre se dedicando em reproduzir em casa os exercícios de estímulo aprendidos com os profissionais.

Houve destaque nas ações promotoras do desenvolvimento do prematuro, onde os pais inserem uma rotina de intervenções para auxiliar no progresso dessas crianças como, por exemplo, estimular a fala, conversando e interagindo com os filhos e utilizando a brincadeira como forma de estimulação:

"[...] eu sempre peço para elas me ensinarem para eu fazer com ele em casa tudo de novo. [...] e em casa eu sempre tento fazer tudo de novo com ele, todo dia pra ele não esquecer." (F03)

"Meu menino de 10 anos pegas uns brinquedo lá e vai perguntando pra ela qual é a cor e tal, aí vai falando:

'Oh E"., essa aqui é verde, esse aqui é tal." (F06) 


\section{Apoio social in(efetivo)}

Com a prematuridade e suas demandas, toda a dinâmica familiar é afetada, incluindo o sistema fraternal. Os irmãos mais velhos necessitam lidar com a ausência dos pais, tendo seus cuidados delegados a outros familiares, além de depararem-se com a ansiedade de não conhecerem o novo irmão, pois muitas vezes são impossibilitados de visitar o binômio no ambiente hospitalar. Os pais relatam um sentimento de culpa por não conseguirem estar presentes com os filhos e, algumas mães mencionam o sentimento de solidão que vivenciam durante a internação:

“[...] foi muito complicado. Porque a gente tem a irmã dela lá em casa não é, então alguém tinha que ficar com ela para eu poder trabalhar e a mãe dela tinha que ficar aqui no hospital. Aí eu saía para trabalhar e ela ficava na casa da vó dela, só de noite que a gente ia pra casa." (F02)

"O período ruim mesmo é o da solidão, que a gente sente não é, quando o pai vinha visitar e depois ia embora, ficava aquela tristeza, a vó, os meus irmãos, sempre dava uma nostalgia, uma vontade de chorar.” (FO5)

Ainda durante o período de internação os pais evidenciam o mérito do apoio da equipe multiprofissional, demonstrando satisfação e gratidão com esse atendimento. As mães nutrizes (puérperas que estão acompanhando seus filhos na UTI) reconhecem a equipe do banco de leite como apoio essencial nesse momento, pois já fragilizadas pelo parto prematuro, temiam não poder alimentar/amamentar o filho internado. Destaca-se, então, a importância do Banco de Leite Humano (BLH) na criação de vínculo da equipe com as pacientes, pois durante a ordenha do leite existia um momento de escuta e orientação entre essas mães e com a equipe:

"As meninas do banco de leite são muito atenciosas, muito boas sabe. Sempre iam lá ver como que a gente estava, se precisava de ajuda." (F07)

"[...] estimulava o peito, porque com 26 semanas não é, quase não tem leite. Aí fazia massagem, ia no banco de leite, as meninas de lá são maravilhosas. Aí as meninas estimulavam pra tirar leite pra dar pra ele." (FO3)

Evidencia-se também a extrema importância do alojamento da mãe nutriz no hospital, que além de permitir que as mães estejam sempre perto do filho, também proporciona um ambiente de compartilhamento de experiências e afeto, onde as mães que possuem seu filho internado na UTIN interagem entre si, criando vínculo e fortalecendo suas redes de apoio.

"As meninas que ficavam lá no quarto eram maravilhosas e eu acho que me ajudou em tudo isso, não é, porque às vezes as pessoas não têm noção do que a gente está passando, só quem vive mesmo." (F06)

\section{DISCUSSÃO}

Esse estudo permitiu a identificação dos conhecimentos, crenças e valores que sustentam as práticas parentais no contexto da prematuridade e a compreensão, a partir da visão dos pais, de como esses fatores influenciam as relações de cuidado e promoção do desenvolvimento da criança nascida prematura. A análise das narrativas, à luz do Referencial Teórico do Interacionismo Simbólico, permitiu desvelar categorias temáticas que representam o processo de significação e de construção da parentalidade, a partir da forma como os pais conceituam a natureza da interação com o filho prematuro. Nesse processo destacam-se as crenças, os medos, as inseguranças, os aprendizados e as práticas parentais que emergem na interação social destes pais com os elementos presentes na vivência da prematuridade. Nessa trajetória, o apoio das redes sociais tem influência na forma como os pais assimilam a condição da criança e desenvolvem suas competências e a parentalidade efetiva.

Com a alta para o domicílio os pais experimentam diversos sentimentos, desde o alívio em deixar o ambiente hospitalar, até os medos e inseguranças advindos de cuidar do filho sozinhos em casa. A insegurança é um sentimento predominante no momento da alta hospitalar, visto que os pais não se sentem preparados o suficiente pela equipe para realizar os cuidados em casa ${ }^{(22)}$.

A promoção do cuidado ao prematuro no domicílio é de extrema relevância para seu desenvolvimento. Ao incluir os pais no cuidado do prematuro ainda no hospital, é possível estimular autonomia e autoconfiança para o manejo do cuidado do filho em casa $^{(23)}$.

Em trabalho realizado na Noruega, a implementação de atividades educativas sobre a transição do prematuro para o domicílio apresentou um impacto positivo na redução do estresse e ansiedade dos pais, além de estimular a confiança destes no que tange aos cuidados prestados ao recém-nascido após a alta hospitalar ${ }^{(24,25)}$. 
Cientes da importância da estimulação para o desenvolvimento do filho, os pais descrevem ações promotoras desse desenvolvimento, como a repetição de atividades que realizam nas terapias de estimulação, a conversa direcionada à criança e brincadeiras como forma de estímulo. Estimulação essa, de extrema relevância para o desenvolvimento do sistema neuropsicomotor, visto que este é multifatorial, inclui aspectos psicológicos, sociais, ambientais e biológicos ${ }^{(26)}$.

A experiência do "brincar" favorece a novas conexões neuronais e aumenta o potencial de aprendizado da criança( ${ }^{(27)}$. A família exerce papel essencial nesse desenvolvimento, podendo proporcionar através das práticas parentais, como as brincadeiras e estímulos sensoriais, experiências adequadas para o desenvolvimento cerebral dessas crianças ${ }^{(28)}$.

Resultados de uma pesquisa apontam a importância de destacar o ambiente domiciliar como um fator essencial para a estimulação, aprendizado e desenvolvimento da criança, devendo sempre levar em consideração suas individualidades e potencialidades ${ }^{(24)}$.

A família influencia diretamente no desenvolvimento das habilidades socioemocionais e comportamentais da criança ${ }^{(29,30)}$. Essas habilidades referem-se a traços de origem psicológica e social, como determinação, autoestima, tolerância e julgamentos morais ${ }^{(31)}$. Habitualmente, as políticas públicas brasileiras não têm priorizado o desenvolvimento dessas habilidades socioemocionais, destacando apenas o crescimento e o desenvolvimento físico e as habilidades cognitivas ${ }^{(28)}$.

A Enfermagem possui um papel de facilitador no processo transacional hospital-domicílio devido à proximidade com os pais dessas crianças nascidas prematuras, proporcionada pela natureza da profissão. A promoção de práticas de cuidado que foquem a construção da parentalidade, fortalecimento da autonomia e autoconfiança contribuem para a redução de impactos negativos dessa vivência e proporciona mais tranquilidade e segurança para esses pais ${ }^{(22,32,33)}$.

A organização da continuidade do cuidado permanece como um desafio. O serviço de referência vinculada à presente pesquisa está localizado na região central de Brasília, caracterizando-se como um fator dificultador para as famílias que vivem no entorno da capital, ou até mesmo em outros estados. Apesar da continuidade do cuidado após a alta hospitalar ser considerada fundamental para a qualidade de vida da criança nascida prematura, a efetivação dessa assistência ainda possui fragilidades no contexto da atenção à saúde da criança no país ${ }^{(34)}$.

As práticas parentais são essenciais para que a competências e habilidades dessas crianças de risco se fortaleçam. Portanto, a importância da promoção dessas práticas parentais no desenvolvimento, tanto das habilidades neuropsicomotoras quanto das competências socioemocionais, deve ser reconhecida, valorizada e estimulada de forma que a família, junto aos serviços de saúde, seja agente ativo na promoção do desenvolvimento na primeira infância ${ }^{(28)}$.

Os cuidados voltados a ações curativas são apenas uma das etapas atribuídas à equipe de enfermagem. Os esforços que estimulem e incentivem a família a ser parte ativa nesse cuidado, tanto na internação, quanto nos cuidados domiciliares, devem ser constantes e contínuos ${ }^{(2)}$.

Entende-se como limitação do estudo, a restrição à realidade de famílias de apenas um serviço de saúde específico. Sugerem-se novos estudos que abordem a temática, com diferentes metodologias, contextos sociais e grupos amostrais inseridos em serviços de diferentes complexidades em saúde de forma a gerar novos conhecimentos e ampliar a compreensão da experiência de parentalidade na situação de prematuridade e, dessa forma, qualificar a assistência à saúde de prematuros e suas famílias.

\section{CONSIDERAÇÕES FINAIS}

Compreendeu-se que os pais reconhecem as características especiais de cuidado e de desenvolvimento do prematuro e, mesmo diante de crenças, medos, inseguranças e do apoio social limitado, investem esforços necessários para cuidar da criança de forma a desenvolver aprendizados e práticas de cuidado efetivas para a promoção do desenvolvimento do filho prematuro.

Em prol da construção de uma parentalidade efetiva frente às necessidades e fragilidades percebidas, a equipe de saúde apresenta atuação estratégica na transição do cuidado para o domicílio, no acompanhamento do desenvolvimento do prematuro e no fortalecimento do apoio social sensível às necessidades da família. Além disso, a criação de programas e estratégias educacionais entre serviços de complexidades diferentes, a exemplo de unidades neonatais e ambulatórios especializados de acompanhamento, pode contribuir para o aprendizado e o desenvolvimento de competências parentais necessárias para o desenvolvimento integral da criança nascida prematura.

A Enfermagem, enquanto frente da equipe de saúde, apresenta competência para focalizar a parentalidade como uma dimensão de avaliação e planejar um cuidado que vise promover a autonomia, a segurança, a eficácia e o bem-estar parental no cuidado desenvolvimental do filho prematuro. 


\section{AGRADECIMENTOS E CONFLITOS DE INTERESSE}

A equipe de pesquisa reconhece o apoio da equipe técnica do ambulatório e do Hospital Universitário para a viabilização da pesquisa. O manuscrito não apresenta quaisquer relações que impliquem em potencial conflito de interesse.

\section{CONTRIBUIÇÕES}

Todas as autoras concordam com a versão final do manuscrito e tiveram contribuições substanciais na concepção e desenho da pesquisa; na aquisição de dados ou na análise e interpretação de dados; na redação e na revisão crítica do manuscrito.

\section{FONTES DE FINANCIAMENTO}

Este estudo contou com o apoio do Conselho Nacional de Desenvolvimento Científico e Tecnológico (CNPq), por meio de concessão de bolsa de pesquisa.

\section{REFERÊNCIAS}

1. World Health Organization [Internet]. Geneva: WHO; c2018 [acesso em 2019 Dez 16]. Preterm birth. Disponível em: https://www.who.int/news-room/fact-sheets/detail/preterm-birth

2. Chawanpaiboon S, Vogel JP, Moller AB, Lumbiganon P, Petzold M, Hogan D, et al. Global, regional, and national estimates of levels of preterm birth in 2014: a systematic review and modelling analysis. The Lancet Glob Health [Internet]. 2019 [acesso em 2019 Dez 10];2(3):e155-64. Disponível em: https://www.thelancet. com/action/showPdf?pii=S2214-109X\%2818\%2930451-0

3. Liu L, Oza S, Hogan D, Chu Y, Perin J, Zhu J, et al. Global, regional, and national causes of under-5 mortality in 2000-15: an updated systematic analysis with implications for the Sustainable Development Goals. Lancet [Internet]. 2016 [acesso em 2019 Dez 10];388(10063):3027-35. Disponível em: https://www.thelancet.com/ action/showPdf?pii=S0140-6736\%2816\%2931593-8

4. Cossul MU, Silveira AO, Pontes TB, Martins G, Wernet M, Cabral CCDO. Crenças e práticas parentais no cuidado domiciliar da criança nascida prematura. REME Online [Internet]. 2015 [acesso em 2019 Dez 10];19(4):830-41. Disponível em: http://www.reme.org.br/artigo/detalhes/1044

5. Zvara BJ, Keim SA, Boone KM, Anderson SE. Associations between parenting behavior and executive function among preschool-aged children born very preterm. Early Child Res Q [Internet]. 2019 [acesso em 2019 Dez 12];48(3):317-24. Disponível em: https://www.sciencedirect.com/science/article/pii/ S0885200619300559

6. Barroso RG, Machado C. Definições, dimensões e determinantes da parentalidade. Psychologica [Internet]. 2010 [acesso em 2019 Dez 12];(52-I):211-29. Disponível em: https://impactum-journals.uc.pt/psychologica/ article/view/996/445

7. Schmidt KT, Higarashi IH. Experiência materna no cuidado domiciliar ao recém-nascido prematuro. REME Online [Internet]. 2012 [acesso em Dez 10];16(3):391-9. Disponível em: http://www.reme.org.br/artigo/ detalhes/542

8. Widding $U$, Hägglöf $B$, Farooqi A. Parents of preterm children narrate constructive aspects of their experiences. J Clin Nurs [Internet]. 2019 [acesso em 2019 Dez 12];28:4110-8. Disponível em: https:// onlinelibrary.wiley.com/doi/pdf/10.1111/jocn.14948

9. Adama EA, Bayes $S$, Sundin D. Parents' experiences of caring for preterm infants after discharge from Neonatal Intensive Care Unit: A meta-synthesis of the literature. J Neonatal Nurs [Internet]. 2015 [acesso em 2019 Dez 15];22(1):27-51. Disponível em: https://www.sciencedirect.com/science/article/abs/pii/ $\mathrm{S} 1355184115001118$

10. Melo MRO, Andrade ISNS. Desenvolvimento infantil e prematuridade: uma reflexão sobre o conhecimento e as expectativas maternas. Rev Bras Promoc Saude [Internet]. 2013 [acesso em 2019 Dez 16];26(4): 548-63. Disponível em: https://periodicos.unifor.br/RBPS/article/view/3122/pdf 
11. Medeiros CC, Franzoi MAH, Silveira AO. Conhecimento e cuidado parental na promoção do desenvolvimento da criança nascida prematura. In: $8^{\circ}$ Congresso Ibero-Americano em Investigação Qualitativa [Internet];2019 Julho 16-19; Lisboa. [acesso em 2019 Dez 15]. p.1580-9 Investigação Qualitativa em Saúde/Investigación Cualitativa en Salud, 2019. v. 2. Disponível em: https://proceedings.ciaiq.org/index.php/CIAIQ2019/article/ view/2370

12. Siqueira MBDC, Dias MAB. A percepção materna sobre vivência e aprendizado de cuidado de um bebê prematuro. Epidemiol Serv Saúde [Internet]. 2011 [acesso em 2019 Dez 15];20(1):27-36. Disponível em: http://scielo.iec.gov.br/scielo.php?script=sci_arttext\&pid=S1679-49742011000100004

13. Skene C, Gerrish K, Price F, Pilling E, Bayliss P. Developing family-centred care in a neonatal intensive care unit: an action research study protocol. J Adv Nurs [Internet]. 2016 [acesso em 2019 Dez 15];72(3):658-68. Disponível em: https://onlinelibrary.wiley.com/doi/abs/10.1111/jan.12863

14. Clandinin, DJ, Connelly FM. Pesquisa narrativa: experiência e história em pesquisa qualitativa. [Narrative Inquiry: experience and story in qualitative research] Tradução: Grupo de Pesquisa Narrativa e Educação de Professores ILEEI/UFU. Uberlândia: EDUFU; 2011.

15. Wright LM, Leahey M. Nurses and families: A guide to family assessment and intervention. Philadelphia: FA Davis and Company; 2012.

16. Feetham SL. Conceptual and methodological issues in research of families. In: Bell JM, Watson WL, Wright LM. The cutting edge of family nursing. Alberta: Family Nursing Unit Publications;1990. p.35-49.

17. Fusch PI, Ness LR. Are we there yet? Data saturation in qualitative research. The Qualitative Report [Internet]. 2015 [acesso em 2019 Dez 15];20(9):1408-16. Disponível em: https://nsuworks.nova.edu/cgi/ viewcontent.cgi?article $=2281 \&$ context=tqr

18. Minayo MCS. Amostragem e saturação em pesquisa qualitativa: consensos e controvérsias. Revista Pesquisa Qualitativa [Internet]. 2017 [acesso em 2019 Dez 20];5(7):1-12. Disponível em: https://editora.sepq. org.br/index.php/rpq/article/view/82/59

19. Lieblich A, Tuval-Mashiach R, Zilber T. Narrative research: Reading, analysis, and interpretation. California: SAGE Publishing; 1998.

20. Blumer H. Simbolic Interactionism. New Jersey: Ed. Pretince-Hall; 1969.

21. Charon R. Narrative and medicine. N Engl J Med [Internet]. 2004 [acesso em 2019 Dez 10];350:8623. Disponível em: https://www.nejm.org/doi/full/10.1056/NEJMp038249?url_ver=Z39.88-2003\&rfr_ id=ori\%3Arid\%3Acrossref.org\&rfr_dat=cr_pub\%3Dpubmed

22. Silva RMM, da Silva Menezes CC, Cardoso LL, França AFO. Vivências de famílias de neonatos prematuros hospitalizados em unidade de terapia intensiva neonatal: revisão integrativa. Rev enferm Cent.-Oeste Min [Internet]; 2016 [acesso em 2019 Out 10];6(2):2258-70. Disponível em: http://www.seer.ufsj.edu.br/index.php/ recom/article/view/940

23. Weis J, Zoffmann V, Egerod I. Improved nurse-parent communication in neonatal intensive care unit: evaluation and adjustment of an implementation strategy. Journal of Clinical Nursing [Internet]; 2014 [acesso em 2019 Dez 05];23(23-24):3478-89. Disponível em: https://onlinelibrary.wiley.com/doi/abs/10.1111/ jocn.12599

24. Kynø NM, Ravn IH, Lindemann R, Smeby NA, Torgersen AM, Gundersen T. Parents of preterm-born children; sources of stress and worry and experiences with an early intervention programme - a qualitative study. 2013;BMC nursing.[Internet]; 2013 [acesso em 2019 Out 10];12(1):28. Disponível em: https://www.ncbi.nlm. nih.gov/pubmed/24313957

25. Goldstein J. (2012). Play in children's development, health and well-being. Brussels: Toy Industries of Europe.

26. Bueno EA, Castro AD, Chiquetti EDS. Influência do ambiente domiciliar no desenvolvimento motor de lactentes nascidos pré-termo. Rev Neurociência [Internet]; 2014 [acesso em 2019 Dez 05];22(1):45-52. Disponível em: http://www.revistaneurociencias.com.br/edicoes/2014/2201/2201original/914original.pdf

27. Neel ML M, Stark AR, Maitre N L. Parenting style impacts cognitive and behavioural outcomes of former preterm infants: A systematic review. Child: care, health and development [Internet]. 2018 [acesso em 2019 
Dez 05];44(4):507-15. Disponível em: https://onlinelibrary.wiley.com/doi/abs/10.1111/cch.12561

28. Pluciennik GA, Lazzari MC, Chicaro MF. Fundamentos da família como promotora do desenvolvimento infantil: parentalidade em foco. São Paulo: Fundação Maria Cecília Souto Vidigal. 2015 https://issuu.com/ fmcsv/docs/fundamentos_fam_lia

29. Colditz P, Sanders MR, Boyd R, Pritchard M, Gray P, O'Callaghan MJ ... Evans T. Prem Baby Triple P: a randomised controlled trial of enhanced parenting capacity to improve developmental outcomes in preterm infants. BMC pediatrics [Internet]. 2015 [acesso em 2019 Dez 05];15(1):15. Disponível em: https://bmcpediatr. biomedcentral.com/articles/10.1186/s12887-015-0331-x

30. Honkoff JP. Protecting brains not simply stimulating minds. Science. 2011;333(6045):982-3.

31. Ribeiro JF, Cavalcante da Silva LL, Lacerda dos Santos I, de Sousa Luz E, Lúcia V, Coêlho M, Maria D. O prematuro em unidade de terapia intensiva neonatal: a assistência do enfermeiro. Journal of Nursing UFPE/ Revista de Enfermagem UFPE. [Internet] 2016 [acesso em 2019 Dez 05];10(10):3833-41. Disponível em: http://bvsms.saude.gov.br/bvs/publicacoes/hfb/trabalho_neonatal.pdf

32. Silveira RDC. Manual seguimento ambulatorial do prematuro de risco. Porto Alegre: Sociedade Brasileira de Pediatria. [Internet]. 2012 [acesso em 2019 Dez 05] 1 ed. Disponível em: https://www.sbp.com.br/fileadmin/ user_upload/pdfs/Seguimento_prematuro_ok.pdf

33. Pinto Braga P, de Sena RR. Estratégias para efetivar a continuidade do cuidado pós-alta ao prematuro: revisão integrativa. Acta Paul Enferm Online[Internet]. 2012 [acesso em 2019 Dez 05];25(6):975-80 Disponível em: http://www.scielo.br/scielo.php?script=sci_arttext\&pid=S0103-21002012000600023

34. Viera CS, Mello DFD. O seguimento da saúde da criança pré-termo e de baixo peso egressa da terapia intensiva neonatal. Texto Contexto Enferm [Internet]. 2009 [acesso em 2019 Dez 15];18(1):74-82. Disponível em: http://www.scielo.br/scielo.php?pid=S0104-07072009000100009\&script=sci_abstract\&tlng=pt

\section{Endereço do primeiro autor:}

Camila Camargo Medeiros

Universidade de Brasília - Faculdade de Ciências da Saúde - Departamento de Enfermagem

Campus Darcy Ribeiro, Asa Norte, Bloco B, Sala 16

CEP: 70910-900 - Brasília - DF - Brasil

E-mail: camilacmedeiros@live.com

\section{Endereço para correspondência:}

Aline Oliveira Silveira

Universidade de Brasília - Faculdade de Ciências da Saúde - Departamento de Enfermagem

Campus Darcy Ribeiro, Asa Norte, Bloco B, Sala 16

CEP: 70910-900 - Brasília - DF - Brasil

E-mail: alinesilveira@unb.br 